on the coppicing powers of certain trees in dry and arid climates.

THE Annual Report of the Society of Arts for 1878-9, shows, as might be expected; that during the past session, a vast amount of good and useful work has been done under its auspices. As to the material condition of the Society the report is favourable, notwithstanding the badness of the times.

THE Report of the Auckland (N.Z.) Institute for 1878-9, speaks of the steady progress of the Society, and the increasing interest manifested by the public in its operations. Several valuable papers on New Zealand natural history have been read.

$W_{E}$ have received a number of little Guides for Science Teaching, issued by the Boston (U.S.) Society of Natural History. The enterprise is creditable to the Society, and the "Guides" seem to us to be handy and trustworthy. Some of them are reprints and second editions. They are- "About Pebbles," by Alpheus Wyatt; "Concerning a Few Common Plants," by G. L. Goodall : "Commercial and other Sponges," by A. Wyatt; a reprint of Mrs. Agassiz's "First Lesson in Natural History;" "Common Hydroids, Corals, and Echinoderms," by A. Wyatt. The last three are very fully illustrated.

WE have received from $\mathrm{Mr}$. J. T. Peacock, the eminent grower of succulent plants, a list of the plants cultivated by him; these comprise cacti, agaves, yuccas, sempervivums, euphorbias, and in fact all plants of a succulent or fleshy nature, many of which have hitherto been much neglected by cultivators. The extent of Mr. Peacock's collection may be judged from the fact that at the present time portions are contained at Sudbury House, Kew, the Alexandra Palace, and the Botanical Gardens, Regent's Park. For the purpose of making this class of Plants more generally appreciated among amateurs Mr. Peacock intends sending the printed list to applicants who send an addressed halfpenny wrapper to Sudbury House, Hammersmith.

THE Algemeine Zeifung reports important anthropological discoveries in Moravia. Excavations have been going on for some months back under the direction of Herr Carl Maschka, a specialist in these subjects, in the Shipka and Tschertowa Dira caves, near Stramberg. The discoveries, it is stated, have been made in layers, carrying the investigator back step by step to the palæolithic age. Stone and bronze weapons, with bones of a variety of animals belonging to different periods, appear to have been found in large numbers.

OWING to the great cost and often very inferior quality of gas, the Colonies and India states that for street lighting the electric light is coming into favour in many parts of Australia, and in South Africa particularly; and when the problem of subdividing the light for use in small houses is satisfactorily solved, it will find a wide field in which it can establish itself more rapidly than will be the case in England.

A JAPANESE paper states that some chemists have discovered a vein of silver at Yuigahara, in Kioto-Fu. The water of a pond in the neighbourhood being discoloured, their curiosity was exciter as to the cause, and a search for minerals in the vicinity resulted in the discovery mentioned.

From the Third Annual Report of the Burton-on-Trent Natural History and Archæological Society, it seems to be in a prosperous condition. It forms one of the Midland Union of Natural History Societies, and the work it is doing is on the whole creditable.

THE additions to the Zoological Society's Gardens during the past week include two Crested Porcupines (Hystrix cristata) from West Africa, presented by Mr. Moses Boyle; a Black-winged Peafowl (Pavo nigripennis) from Cochin China, presented by the Hon. A. S. G. Canning, F.Z.S. ; a Buff-backed Egret (Ardea russata), European, six Small-scaled Mastigures (Uro- mastix microlepis) from Busreh, presented by Capt. Burke, s.s. Arcot; a Gold Pheasant (Thaumalea picta) from China, presented by Mr. J. E. Liardet; two Common Barn Owls (Strix fammea), European, presented by Mr. R. A. Baldwin; an Indian Python (Python molurus) from India, a South American Rat Snake (Spilotes variabilis) from South America, presented by Mr. George Billett; two Elliot's Guinea Fowls (Numida ellioti), four Vulturine Guinea Fowls (Numida vulturina) from East Africa, deposited; a Striped Hyæna (Hyana striata) from India, a Yellow-footed Rock Kangaroo (Petrogale xanthopus), four Black Swans (Cygnus atratus) from Australia, two Balearic Cranes (Balearica pavonina), four Rose-ringed Parrakeets (Palceornis docilis) from West Africa, two Siamese Pheasants (Euplocamus pralatus) from Siam, a Darwin's Pucras Pheasant (Pucrasia darwini) from China, purchased; a Japanese Deer (Cervus sika), born in the Gardens; three Australian Wild Ducks (Anas superciliosa), a Spotted-billed Duck (Anas pacilorhyncha), six Rosybilled Ducks (Metopiana peposaca), bred in the Gardens.

\section{HOLLWAY'S NEW APPLICATION OF RAPID OXIDATION BY WHICH SULPHIDES ARE UTILISED AS FUEL 1}

THIS process has for its object the utilisation of the heat generated by the rapid oxidation of certain mineral substances, which have not hitherto been used as sources of heat for smelting operations. The heat thus obtained is employed in the reduction of the furnace charge, which may be composed partly of sulphides and partly of siliceous ores. A current of air is forced through molten sulphides, by which means they are very rapidly oxidised. Great heat is thus developed, rendering the process of smelting a self-supporting operation; therefore no extraneous fuel is required, excepting that employed in raising steam for the blowing engines; where, however, water power is available, steam can be dispensed with, in which case all the carbonaceous fuel necessary for the operation is a little coke to start the furnaces, which stands in the same relative position to the ores as wood does to coal in the lighting of an ordinary fire.

It is well known that pyritous minerals are readily combustible, but the best means of utilising the heat-producing property of metallic sulphides is not so apparent as would at first sight appear. Of these sulphides only iron pyrites is sufficiently com. bustible at a low temperature to burn in the open air, the mass being raised to the temperature at which the oxidation takes place solely by the union of sulphur and iron with atmospheric oxygen. In Spain there are numerous deposits of poor cupreous pyrites, and the Rio Tinto and Tharsis Companies annually treat, at their mines, about one million tons for the extraction of copper only, which does not average 2 per cent. The process employed consists essentially in roasting the pyrites in heaps in the open air, dissolving out the copper from the roasted material, and precipitating it from the solution by means of iron. These operations extend over several months; any gold or silver contained in the ore is lost, and the iron and sulphur are also wasted. The sulphur passes into the air as an obnoxious and annoying gas, desolating the country for miles around the works.

From the earliest ages, carbon has been considered a necessity in all metallurgical operations. The first reduction of metals by means of carbon forms a connecting link between the age of stone and the commencement of civilised art. It is well known that carbon burns at widely varying temperatures, as, for example, in our bodies, in a common coal fire, or in a furnace. A great deal of thought has been devoted to the subject of economising carbonaceous fuel, and great advances have been made in this direction; yet the expenditure of coal or coke necessary, say, to melt a given quantity of metal, still far exceeds the theoretical limit. The main causes of this discrepancy may be accounted for as follows :-

I. Only part vi the oxygen of the air passing into a furnace, acts on the material to be burnt.

2. The oxygen is not brought in contact with the combustible matter with sufficient rapidity, to obtain the necessary temperature for the operation.

3. Gases pass off hot and unburnt. These are now, however, frequently utilised.

x Communicated by Mr. Hollway. 
There is one metallurgical operation in which the first two sources of loss are avoided, viz., "Bessemer's," where, by blowing air through molten crude iron, a very high temperature is attained by the combustion of small quantities of carbon and silicon contained in the crude iron; this is, however, not the case in the process of puddling, where the oxidation is spread over a considerable period of time, although the same constituents are frequently burnt in similar proportions. But even in the Bessemer process the carbon is only half burned, and a large amount of heat escapes with the carbonic oxide and nitrogen.

When, however, thin streams of air are forced through molten sulphide of iron, lying on a tuyère hearth, a high temperature is produced by the perfect combustion which ensues in the midst of the sulphides, and no umburnt gases, excepting nitrogen and sulphur vapour, escape from the surface of the molten mass. The hot nitrogen and sulphurous acid may be caused to act upon iron pyrites and other mineral matter, and when pyrites is thus heated, an atom of sulphur held in feeble combination is in great part expelled, and thus is obtained molten protosulphide of iron, which is subsequently burnt by the oxygen of the air driven in at the lower part of the furnace, thereby producing the heat necessary for continuing the operation. The process may be defined as a system of fractional oxidation, in which the numerous constituents of a complex furnace charge can be separated from each other and concentrated in different parts of the apparatus, the heat necessary for the operation being obtained by the combustion of a portion of the less valuable constituents.

The principal ores of all our ordinary heavy metals, except manganese and tin, are sulphides. Iron, although largely occurring in an oxidised form, is abundantly found in combination with sulphur; and bisulphide of iron, or iron pyrites, is an example of sulphurous and combustible minerals. Associated with iron and sulphur in iron pyrites are invariably found small quantities of other metals, notably cobalt, nickel, copper, silver, gold, lead, zinc, and arsenic. Of these, zinc is almost as combustible as iron itself, while lead and arsenic readily volatilise as sulphides, and cobalt, nickel, and copper are distinctly less readily oxidisable than iron, while silver and gold do not oxidise under these conditions ; hence, in supplying air to such material, the iron is the first of the elements to suffer oxidation, so that if the oxidation be arrested before the whole of the iron has been burnt, the cobalt, nickel, copper, silver, and gold present will be found in the unburnt portion. This principle finds a parallel in the Bessemer process of treating pig-iron for the manufacture of steel, where a current of air is caused to bubble up through a bath of molten crude iron, \{the silicon is first oxidised, and is closely followed and to a great extent accompanied by the carbon, and no large amount of iron suffers oxidation, until the whole of the silicon and carbon have been burnt out of the molten material.

The experiments made at Messrs. Cammell's works, at Penistone, in a Bessemer converter, have proved that by blowing air through molten sulphide of iron, the iron and a portion of the sulphur are oxidised, and if the oxidation is arrested before the combus tion of the iron is complete, a heavy matt or regulus is obtained, which contains but a small proportion of the iron of the ore, but practically the whole or the greater part of the copper and other less oxidisable metals. In one of these experiments the molten sulphides were run into the converter from cupola, in which they had been previously melted, and the tem. perature was kept up until the operation was discontinued, viz., for a period of ten hours, without the use of any carbonaceous fuel, the heat being entirely derived from the oxidation of the iron and a portion of the sulphur of the lumps of pyrites, which were continuously thrown into the mouth of the converter. A Bessemer converter being unsuited for the collection of the gaseous products, the later experiments have been made in a series of cupola fumaces belonging to Messrs. John Brown and Company, Limited. These experiments have proved the possibility of obtaining a valuable regulus, a slag nearly free from copper, and a considerable quantity of crude sulphur. M. Pourcel, the well-known chemist of the Terrenoire Company, has also made some very interesting experiments, having treated by this method a cupriferous sulphide of antimony containing lead and zinc, using heavy spar and silica as fluxes; he obtained a regulus containing the whole of the copper in the form of sulphide, a slag of light specific gravity, and the lead, zinc, and antimony as two separate sublimates which were condensed in different parts of the apparatus, owing to the superior volatility of sulphide of lead over the oxides of antimony and zinc. In the experiments at Penistone and at Sheffield a cold blast of air was employed, and the gases which passed from the converter or furnace into the open air, carried away with them a large amount of heat. In practice, however, it would be economical to employ a hot blast, which could be heated by the waste heat from the escaping gases. It is remarkable that the least valuable metals, viz., iron and zinc, generate by their combustion the largest quantities of heat.

The process may be employed for the reduction of even the more volatile metals ; for example, Mr. A. H. Allen, of Sheffield, has thus obtained metallic antimony simply by the oxidation of sulphide of antimony. It is well known that sulphide of lead reacts upon oxide of lead with the production of metallic lead and sulphurous acid. If, therefore, a limited amount of air is blown into molten sulphide of lead, the oxide thus formed in the lower part of the furnace will, in passing upward, come in contact with the hot sulphide of lead, and metallic lead will result, with the evolution of sulphurous acid. The furnace having a quiescent hearth below the tuyères, the metallic lead will collect there, and can be from time to time withdrawn. A limited amount of air must be employed, because if it is driven in too quickly, the sulphide of lead will rapidly distil off. In thus treating argentiferous lead ores, the silver (and gold if present) would be found with the first metallic lead reduced. When thus treating galena the furnace should have a basic lining.

The process is peculiarly suitable:-

Ist. For the treatment of metalliferous substances which cannot bc advantageously treated by other processes. For the extraction of sulphur by distillation, and simultaneously for the concentration and separation of cobalt, nickel, copper, silver, and gold from minerals in the form of metallic regulus; while lead, zinc, antimony, arsenic, \&c., accrue in the sublimates.

2nd. For the treatment of complex ores, for example-Grey antimonial copper ores, such as those experimented on by $\mathrm{M}$. Pourcel. Ores similar to those worked at the well-known Bottino Mines, Seravezza, in the Italian Apennines, which contain thirteen or fourteen heavy metals, including silver and lead, for which latter alone they have been worked for centuries. The blende of lead mines, in Derbyshire termed "muck," usually thrown away by the miners, because the large quantity of lead with which it is associated renders the zinc obtained from it worthless.

3 rd. For the treatment of auriferous and argentiferous pyrites. It is well-known that in practice it is not possible to obtain the whole of the gold from pyrites by amalgamation with quicksilver, because the presence of sulphur and arsenic sickens and flours the mercury, whereas by fusion the whole of the silver and gold present is obtained.

4th. For the treatment of pyrites containing even only small percentages of cobalt, nickel, and copper, which are thus con. centrated into a rich regulus, whereas this result is now only obtained by very tedious processes of alternate roasting and reduction. Such ores containing Io per cent. and even 12 per cent. of copper exist in South America and many other parts of the world, but are not at present capable of economic treatment, owing to the difficulty of obtaining a sufficient supply of cheap fuel. The process can also be advantageously applied to the treatment of richer ores of copper such as are at present smelted at Swansea.

5th. For the treatment of poor lead ores. If such ores are added to a furnace charge of cupreous pyrites, the silica they contain will be utilised and combine with the resulting oxide of iron to form slag, the galena will be volatilised and be recovered as a sublimate, while any silver present will enrich the regulus. At present, by a costly process of crushing and washing these ores, the galena is concentrated, although a large proportion is left with the debris, and passes with the water into the streams, rendering the existence of fish in such waters impossible. The water power now used for washing the ore could, in many cases, be employed for producing the blast.

When thus treating cupriferous iron pyrites, four products are obtained :-

Ist. A matt or regulus containing from 30 to 50 per cent. of copper, any traces of cobalt, nickel, silver, or gold the ore may contain, the rest of it being iron and sulphur; it has a specific gravity of $4 \frac{1}{2}$ to 5

2nd. A slag consisting of silicate of iron from the resulting oxide of iron combined with the siliceous matters contained in the ore and the fluxes added. 
3rd. Sublimed sulphur, more or less mixed with volatile compounds of lead, zinc, and arsenic.

4th. Sulphurous gases, consisting mainly of sulphurous acid and nitrogen.

The regulus closely resembles, and will replace, the coarse metal of the Swansea copper process, which is now only obtained at considerable cost of labour, time, and carbonaceous fuel. When, however, sulphides of iron and copper present in the bath are treated continuously by a blast of air, a point is at length arrived at when the whole of the iron is oxidised, and the regulus in the bath consists of sub-sulphide of copper. If, now, a limited supply of air is introduced, the copper is re. duced to the metallic state with the evolution of sulphurous acid.

The slag obtained in the Penistone experiments was essentially silicate of iron, containing about 50 per cent. of iron and 29 per cent. of silica. It had a density of about 38 to 4 , and was in composition somewhat allied to the copper-smelter's ore furnace slag and to the tap-cinder of the iron-puddler. By the addition of calcareous materials, the specific gravity of the slag is so reduced as to cause it to separate readily from the regulus which collects below it. In one of the later experiments, when lime was used, the proportion of copper lost in the slag was very small. This is, of course, a most important point, for when dealing with ores containing but little copper, the presence of even a small percentage in the slag means the loss of a considerable proportion of the copper present. These slags can be utilised for the manufacture of steel, being practically siliceous iron ores free from phosphorus, and their reduction in a blast furnace can be profitably effected, as the proportion of iron present is high as compared with the weight of the material; indeed, it may be possible to reduce them while in a molten state.

By re-subliming the crude sulphur, it can be freed from all impurities except arsenic, and at the works of Messrs. John Hutchinson and Co., Widnes, this is eliminated by means of polysulphide of calcium.

As a certain proportion of the sulphur of the minerals suffers combustion, the resulting sulphurous gases contain from 14 to 15 per cent. of sulphurous acid, and hence the proportion of sulphurous acid to nitrogen is nearly identical with that of the gases produced by roasting pyrites in the kilns employed by vitriol manufacturers, and can, therefore, be used with equal advantage for the production of vitriol in leaden chambers. This appears to be the simplest solution of the great problem how to smelt copper without causing a nuisance to the surrounding neighbourhood, although a similar result might be obtained by collecting and liquefying the sulphurous acid.

The more incombustible materials it is found practicable to employ without too great a loss of temperature, the wider will become the application for the process; for there are many ores, including silicates and carbonates, containing metals in the form of oxides, which might be convenientiy smelted by mixing them with a sufficient proportion of pyritous ores to effect their reduction; in fact, one of the chief practical questions connected with this process is how far it may be trusted to effect the smelting of ores or furnace charges containing comparatively moderate proportions of sulphides. It is evident that it will almost entirely obviate the necessity for using carbonaceous fuel, at least as far as the production of a regulus is concerned, and consequently the localities in which smelting operations may be advantageously carried on are thus greatly multiplied. One of its chief merits is that it is equally applicable with comparatively little extra cost in the working, to very poor and very rich ores, for however small the resulting regulus, it will contain nearly the whole of the cobalt, nickel, copper, silver, and gold present in the furnace charge, while any lead, zinc, antimony, and arsenic will be obtained as sublimates.

\section{UNIVERSITY AND EDUCATIONAL \\ INTELLIGENCE}

THE authorities at Owens College, Manchester, and of the Yorkshire College of Science, Leeds, have already taken the initiatory steps for preparing a constitution of the new University for the North of England, for which a charter has recently been granted. The Council of the Owens College have appointed a committee of their body, and on Friday they met in conference at the college in Mancliester, with representatives of the Council of the Yorkshire College of Science, for the purpose of consi- dering a draft constitution for the new institution. The basis of the deliberations of the conference is to be found in the series of suggestions contained in an appendix to the memorial which was presented to the Privy Council some time ago, but various questions will come before the meeting for consideration, including the power of granting degrees to women and the better representation of the graduates and the teaching staff upon the Board. of Governors. Considerable progress was made on Friday in preparing suggestions for a draft of a proposed charter, though each of the clauses was very fully discussed before adoption. When the conference has completed its task it will report to the Council previous to the scheme being submitted to the Law Officers of the Crown.

Mr. W. N. HaRTley, of King's College, London, has been appointed Professor of Theoretical and Practical Chemistry in the Royal College of Science, Dublin, and enters upon his duties at the beginning of the October term.

THE following students have passed the examinations which entitle them to the distinction of "Associate of the Royal School of Mines":- In the Mining and Metallurgical Divisions : Mirza Mehdy Khan. In the Mining Division: W. E. Benton, A. G. Charleton, A. D. Ellis, E. N. Fell, H. B. Statter, H. Strickland. In the Metallurgical Division: W. B. M. Davidson, A. H. Fison, F. W. Grey, E. Halse, E. W. Harvey, Malcolm Hill, J. H. Lucas, Walter Marsh, A. Gordon Salamon. The two Royal Scholarships of $\mathrm{I} 5 l_{\text {. }}$ each have been awarded to $J$. J. Hood and J. F. Wilkinson. The Royal Scholarship of 25l. has been awarded to Ralph G. Scott; the De la Beche Medal for Mining to A. D. Ellis ; and the Murchison Medal for Geology to B. Mott.

\section{SCIENTIFIC SERIALS}

American Fournal of Science and Arts, June.--Reviewing what is now known of extra digits in the feet of the modern horse Prof. Marsh says the instances fall naturally into two groups : the first comprising simply cases of reduplication (like that of the occasional extra-finger in the human hand), not satisfactorily explained as yet; the second includes cases where a true digit is formed, the component bones in normal position and relation, and such instances seem clearly due to reversion to some ancestral type. Extra digits appear more frequently on the fore feet than the hind feet (as a study of fossils would lead one to expect), and more frequently on the inside of the main digit, the outer splint remaining rudimentary (this, again, is opposed to the general law of reduction in the ungulate foot). Mr. Sargent's paper on the forests of Central Nevada has been elsewhere referred to, and we further note that Prof. J. C. Draper writes on the dark lines of oxygen in the solar spectrum on the less refrangible side of $G$ (in the regions about $\lambda$ 43I 7 and $\lambda$ 4319); Mr. Christy seeks an answer to the question "Are cinnabar deposits produced by sublimation, or are they deposited from solution?" and concludes that they are the immediate result of the action of solutions of alkaline carbonates containing also alkaline sulphides; Mr. Hodges suggests a new absolute galvanometer,-Mr. Sawyer contributes a first catalogue of radiant points of meteors (from observations at Cambridge during the last two years); and Maria Mitchell notes on the satellites of Saturn. - A recent paper published in Brazil, by Mr. Derby, on the geology of the Lower Arizonas, is summarised by Mr. Rathbun.

Fournal of the Franklin Institute, June.-We note here the following:-Pealicellier's compound compass and other linkages, by Prof. Marks.-Some experiments on alloys of silver witl embrittling metals, by Mr. Outerbridge,--Phosphorus in coal, hy Mr. McCreath.-On the determination of silicon in pig-iron and steel, by Dr. Drown.

Reale Istituto Lombardo di Scienze e Letlere. Rendiconti. Vol. xii. fasc, xi,-xii,-On an integral formula, by Prof. Beltrami.-On tetrahedral systems, by S. Aschieri.-Atrophy and degeneration, by Prof. Sangalli.--On a parasite Colothurnia of the branchize of our crabs, by Prof. Maggi.-A microphyte on Hesperidex, by Dr. Cattarneo.-The infirmity of Torquato Tasso, by Prof. Conadi. - A new bird for the Lombardy fauna, by Prof. Pavesi. - On the centre of forces in the plane, by Prof. Bardelli. On the cortical iridian centre in birds, by S. Ortel. - New series of researches on the pelagic fauna of the Italian lakes, by Prof. Pavesi. 